
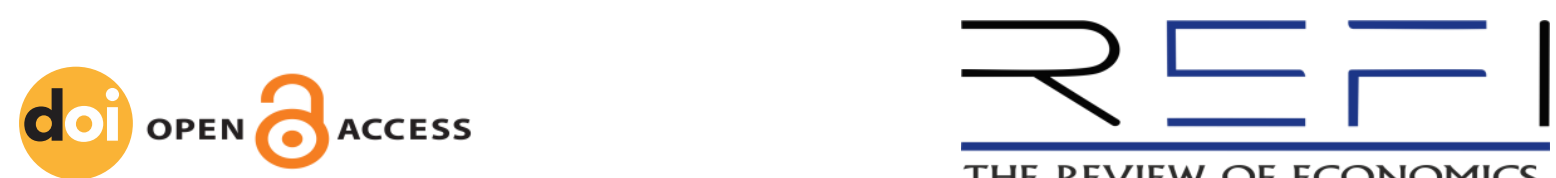

THE REVIEW OF ECONOMICS, FINANCE AND INVESTMENTS

\title{
Speculation in the Cryptocurrency Market
}

\author{
By PAWEŁ MILKA*
}

\begin{abstract}
The article analyses the impact of speculation on the cryptocurrency market. In the introduction, the author interprets the meaning of the word speculation and a speculator's way of thinking. The literature review was broken down into two aspects. The first is to analyse the literature on the subject in terms of the cryptocurrency market. The second is an analysis of the sentiment index, which becomes the primary research method. The analysis of the sentiment value shows a high correlation between the impact of sentiment on the value of cryptocurrencies. Further recommendations are to analyse the sentiment with regard to listed companies (Polish and international) and stock indices (including the forex market).
\end{abstract}

JEL Classification: D84, E40.

Suggested citation: Milka, P. (2020). Speculation in the Cryptocurrency Market. The Review of Economics, Finance and Investments, 1(1), 24-33.

\section{INTRODUCTION}

The speculation process has been known for centuries. All it takes is to try to predict whether, for example, a war would break out, the grain harvest would be larger or poorer in a year's time, and to make appropriate commercial transactions on the market. It can be argued that speculation is betting on an uncertain future. Following this line of reasoning, speculation can be defined as an unconventional type of trade. In the past, people traded in weapons, grain, iron, etc. Currently, you can trade commodities (also known for centuries), stocks, index futures, etc. In speculation, the purchased commodity is not consumed but held and sold at a higher price at a later date. What price? One that will satisfy the speculator, i.e. in this line of reasoning - a trader with particular goods.

The main difference between a classic commodity trader and a speculator is the concept of time. As mentioned above, a speculator needs time for the price of the commodity he is speculating on to rise or fall - depending on the position taken. The price depends on the function of time, and the difference between the selling price and the buying price will give the result of the transaction, i.e. the result of speculation.

Investor behaviour is also crucial in speculation. Many of them fall into the trap of overthinking. Kahneman (2012) divides the way of thinking and perceiving things into two systems. The first system is emotional thinking - according to research, this system is typical for the largest group of investors. The second system is based on calm and logical reasoning. This system should be characteristic of investors but is typical of speculators. Kahneman highlights that people will look at the same event differently, think differently and draw different conclusions. This thought is extremely important from the standpoint of trying to predict the future, which is the essence of speculation. The author writes in his book:

\footnotetext{
* Paweł Milka, Assistant Professor and PhD Student at Cracow University of Economics (Poland); ORCID: 00oo-0002-6276-7587; email:milkap@uek.krakow.pl.
} 
"The idea that the future is mysterious has to face a daily struggle with how easy it is for us to explain the past. (...) The illusion that we understand the past awakens in us an excessive belief in our ability to predict the future."

In line with Kahneman's conviction that people make predictions about an unknown future based on past phenomena, it should be noted that traders are making a technical analysis of the charts to try to predict what may happen in the near future. It should be highlighted at this point that the technical analysis is a record of a chart that shows the emanation of the market struggle between buyers and sellers, bulls and bears that took place in the past. The chart of stocks of listed companies, indices, and cryptocurrencies shows a record of transactions that took place in the past. It does not indicate why market players bid or ask. It does not show a list of bids placed for a given asset; it does not indicate the reasons for withdrawing some of them. It is not looking for answers to various questions. The chart reflects market euphoria and panic. The speculator will try to buy rumours and sell facts. A speculator will want to sell their assets in times of the greatest euphoria and buy them when panic hits the market. They will convince everyone that their product is of the highest quality so that they can sell it as expensive as possible. They will try to prove that its price is very attractive to potential buyers. However, when selling particular goods, they will reverse this polemic and find that the goods bought are overvalued or worthless.

It should also be remembered that financial markets are much like living entities. A speculator is aware of a potential failure; they know there is an investor on the other end, possibly a speculator too, who also wants to make a profit.

The market is a field of competition in which speculators try to trick others into believing that a given product is of better or worse quality so as to buy it cheaper or sell for more. It should also be remembered that the market is limited in terms of money supply. Therefore, only some market players can say that they have made a profit. This is due to a simple dependency. If someone made money, someone else had to lose it. The speculator's goal is to play an either/or game. The speculator either earns at the expense of others or loses. Market cash flow is not an open system. The cryptocurrency market is a perfect example of the speculators' game related to wealth and bankruptcy.

\section{LITERATURE REVIEW}

The literature review was broken down into two aspects. The first is to analyse the literature on the subject in terms of the cryptocurrency market. The second is the analysis of the sentiment index.

Rafikov (2017) noted that according to the McKinsey Global Markets Report 2011, the total value of global financial assets, both debts and equity, at the end of 2010 totalled $\$ 212$ trillion. For comparison, in 2011, real assets amounted to USD 61.96 trillion. It has to be noted that the over the counter derivatives market amounted to USD 601 trillion at the end of 2010. So, having presented such data from nearly a decade ago, it is worth asking how the real world output of $\$ 62$ trillion in 2010 can support assets worth over $\$ 800$ trillion. The forex market in the given period amounted to $\$ 4$ trillion in daily currency trading. So, as one can easily see, speculating on the financial markets is not hard to come by. Choudhury (2009) recognised that speculation was caused by the uncertainty related to the futures contracts actively entering the financial markets. Due to such circumstances, speculators may profit from these contracts in the future. Based on their profit expectations, they will shift funds between the real economy sector and the financial market. Ashley (2010), quoting J.M. Keynes in The General Theory of Employment, Interest and Capital, states that speculation is "an activity of predicting the psychology of the market." He described the motive behind speculation as "the goal of making a profit through knowing what the future holds better than the market does". Kamali (2002) states that speculation is an integral part of any business. He also notes that speculation and risk-taking are facts of modern commerce, no matter how careful one is. Bear (2020) believes that speculation is related to fictitious values driven by excessive emotions and not the actual value of assets. He also notes that in Marx's ideology, the inevitable decline of the profit rate under capitalism provoked overproduction, speculation, and crisis. Bear $(2015,2020)$ believes that corporations have become a hybrid connecting government, financial and manufacturing institutions. Contracts between the market and the state were crucial for these connections, with particular emphasis on sovereign debt, which was transformed into bonds, tradable 
on financial markets. State power was directed to provide capital of a speculative nature (Gabor \& Ban, 2016; Goldman, 2011). Bear (2020) states that since the beginning of the 1990s, commerce has been mechanised through numerous algorithms. These processes significantly accelerated trading, which increased the rate of speculation in the financial markets. The associated volatility with this phenomenon has accelerated speculation across society.

The current speculation is less visible as it has developed most in privately invested contracts and in the shadow economy - mainly in investment funds (Fernandez \& Wigger, 2016). Many global banks were hit hardest by the crisis of 2007-2009. These banks were linked to the aforementioned investment funds. Many researchers state that banks, as financial intermediaries, appropriated the ability to decide about the global financial system. In spite of this, virtual money, unmanaged by anyone, has been introduced into the world - cryptocurrencies.

Digital currencies are attractive in the sense that they have an impact on the entrenched world of finance and central banking, two entities that share the responsibility for actions or omissions during the financial crises of Asia and the banking crisis of 2007-2009. Therefore, cryptocurrencies can undermine the power of financial institutions that charge high commissions while generating substantial profits. Moreover, cryptocurrencies may undermine the power of central banks to conduct monetary policies (Solimano, 2018). The digital mechanism on which digital money is based is presented in a paper written by a programmer introducing himself as Satoshi Nakamoto. The three main properties presented by Nakamoto are: decentralisation in transaction approval, encryption and proof-of-work properties, and the fact that records of all transactions in the ledger cannot be deleted, changed or undone.

Bitcoin - the most important cryptocurrency - accounted for 38 percent of market transactions and 47 percent of transaction value in cryptocurrencies (IMF, 2018). According to the International Monetary Fund (IMF, 2018), total cryptocurrency trading accounted for nearly 4 percent of the balance sheets of major central banks. Until a few years ago, this share was practically zero. Much research on the Bitcoin market focused on revealing prices and the transparency of the Bitcoin futures market. Many researchers tried to identify the impact of fundamental factors on cryptocurrency prices (Bhambhwani, Delikouras, \& Korniotis, 2019; Nekhili \& Sultan, 2020). Sebastiao and Godinho (2019) analysed the impact of Bitcoin futures on the cryptocurrency market, concluding that Bitcoin futures can be used to hedge other cryptocurrencies. However, there are studies (Corbet, Lucey, Peat and Vigne 2018) on the dynamics of Bitcoin's spot-price volatility following the introduction of Bitcoin futures. Their results confirmed that Bitcoin's spot-price volatility had increased, and this called into question the effectiveness of Bitcoin futures as a hedging instrument. In the subject literature on cryptocurrency hedging, Karkkainen (2018) argued that the Bitcoin futures market opened up opportunities for both hedgers and speculators.

The cryptocurrency paradox, and especially the one discussed in large numbers in the Bitcoin literature, is that, being an inherently worthless computer record, it is characterised by a high price (also price amplitude) (Solimano, 2018). The price increased from less than $\$ 1$ in 2010 to $\$ 64,899.97$ on 14 April 2021. Many economists ask themselves whether cryptocurrencies (including Bitcoin) can be called money. Keynes distinguished three main motives of the demand for money: transactional, prudential and speculative. Some scholars (Hale, Krishnamurthy, Kudlyak, \& Shultz, 2018) believed that Bitcoin's speculative dynamics had gone. However, as the years 2020 and 2021 have shown, Bitcoin's speculative motive exists and grows ever stronger. This motive is most likely with Bitcoin and other cryptocurrencies. This article will try to answer the question of whether and how individual investors may be able to speculate in the cryptocurrency market.

The research method used to study cryptocurrencies is the analysis of the investor's sentiment. Research into analysing investor sentiment that can affect financial markets has long been the subject of research by behavioural economists. For example, Barberis et al. (1998) examined the role of investor sentiment in financial markets. De Long et al. (1990) proposed models in the field of behavioural finance, assuming that investors are driven by sentiment. Baker and Wuger (2007) and Da, Engelberg, and Gao (2015) find that investor sentiment explains equity returns and has a greater impact on equities that are more difficult to make an arbitration transaction. Da, Engelberg and Gao (2015) report that these are shares of companies that are characterised by a higher beta parameter, higher volatility and an 
increased risk of a bear market. Another aspect recognised by the above researchers is the fact that investor sentiment is subject to a reversal, i.e. increases or decreases in investor sentiment are matched by low or high returns on capital. However, attention is also drawn to the dependence stating that this relationship is reversed in the days following market transactions. As A. Brochado (2020) states, significant improvements have been made in recent years in the techniques of tracking investors' moods thanks to the continuous development of social media, analysis of the content posted there and Internet search data. The author, confirming the research of economists, believes that the analysis of the aggregate flows of investment funds in domestic equity funds (Beaumont, van Daele, Frijns, Lehnert, \& Muller, 2008) and the shifts of risky assets made by retail investors against institutional ones (Edelen, Marcus, \& Tehrnian, 2010) gave high scores against sentiment analysis, as these models were easy to construct and were objectively observable by researchers.

Given the above, this article aims to analyse the sentiment of Bitcoin and Ethereum in the context of speculation on these cryptocurrencies.

\section{DATA AND RESEARCH METHODOLOGY}

The article collects data from 1 January 2016 to 1 June 2021 against the price of two cryptocurrencies: Bitcoin and Ethereum. These data were processed taking into account the following values: the highest, lowest and average price, the values of the refresh rate, the number of falling and rising days and changes in daily prices (only the maximum and minimum values and the price change for the analysed period will be presented). The study results are presented in Tables 1 and 2.

Table 1. Data on the Bitcoin cryptocurrency in the period 01.01.2016 - 01.06.2021

\begin{tabular}{|l|l|l|l|l|l|l|l|l|l|l|l|l|}
\hline \multicolumn{2}{|l|}{ Price } & \multicolumn{3}{l|}{ Refresh Rate } & \multicolumn{3}{l|}{ Up/Down } & \multicolumn{2}{l|}{ Price Change (Close-Close) } \\
\hline High & $64,899.97$ & 14.04 .2021 & Max & $7,969,551$ & 30.05 .2021 & Advancing & $303,533,869$ & Up & 1049 & Up & $+42.19 \%$ & 05.04 .2018 \\
\hline Low & 352.10 & 16.01 .2016 & Min & 5,266 & 22.04 .2018 & Declining & $266,088,630$ & Down & 895 & Down & $-28.19 \%$ & 07.04 .2018 \\
\hline Avg & $9,303.60$ & & Avg & 433,612 & & Total & 570199568 & Unch & 1 & $\begin{array}{l}\text { Period } \\
+8,268.45 \% \\
- \\
01.06 .2021\end{array}$ \\
\hline
\end{tabular}

Source: Author's own work

Table 2. Data on the Ethereum cryptocurrency in the period 01.11.2018 - 01.06.2021

\begin{tabular}{|l|l|l|l|l|l|l|l|l|l|l|l|l|}
\hline \multicolumn{2}{|l|}{ Price } & \multicolumn{3}{l|}{ Refresh Rate } & \multicolumn{2}{l|}{ Up/Down } & \multicolumn{2}{l|}{ Price Change (Close-Close) } \\
\hline High & $4,384.95$ & 12.05 .2021 & Max & $4,831,216$ & 31.05 .2021 & Advancing & $184,480,876$ & Up & 458 & Up & $+38.28 \%$ & 24.05 .2021 \\
\hline Low & 80.73 & 16.12 .2018 & Min & 28,955 & 27.02 .2019 & Declining & $141,871,580$ & Down & 422 & Down & $-33.69 \%$ & 12.03 .2020 \\
\hline Avg & 522.80 & & Avg & 362,373 & & Total & $330,484,067$ & Unch & 61 & $\begin{array}{l}\text { Period } \\
+1,210.55 \% \\
- \\
01.06 .2021\end{array}$ \\
\hline
\end{tabular}

Source: Author's own work

The Ethereum cryptocurrency analysis examined the period from 2018, as the value of ETH before November 2018 was small, and the volatility of prices did not reflect the boom of the BTC cryptocurrency.

The analysed ETH and BTC prices are shown in Charts 1 and 2.

Chart 1. BTC value in the period 01.01.2016 - 01.06.2021 


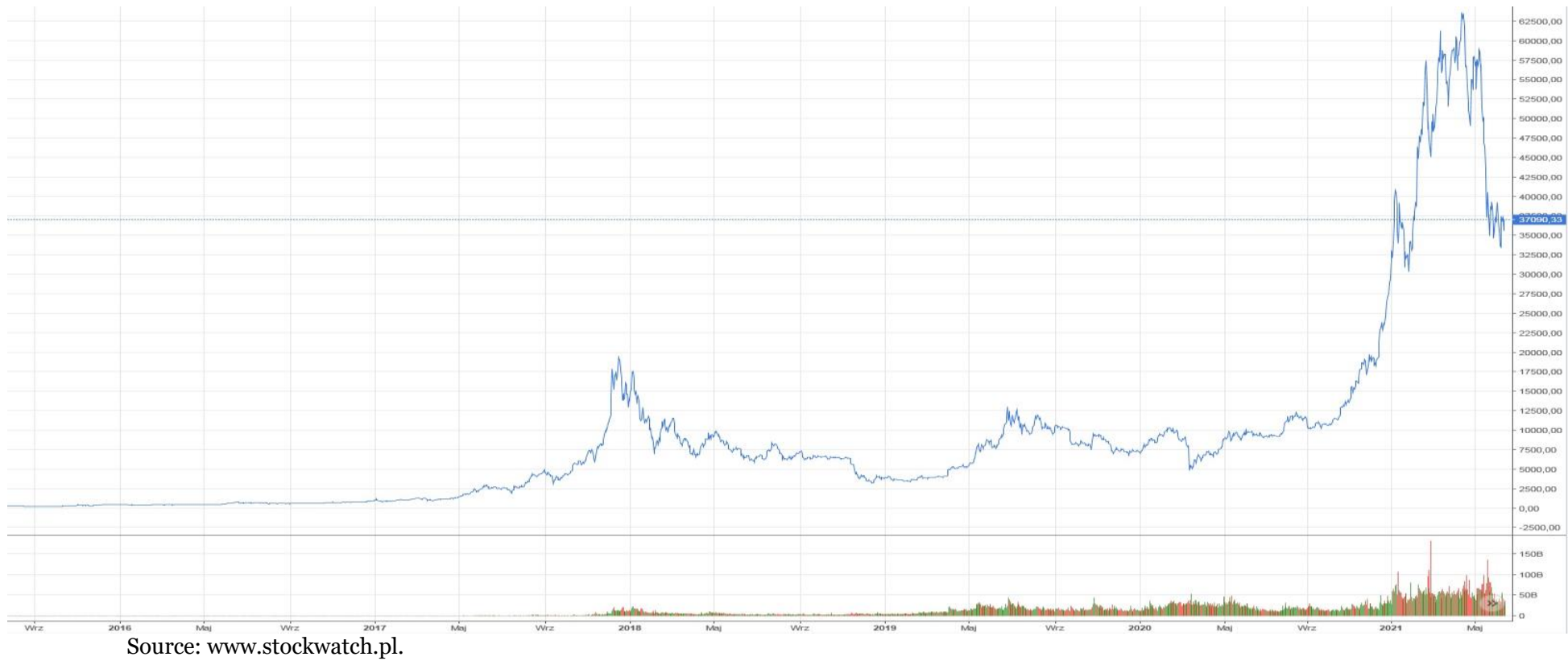

Chart 2. ETH value in the period 01.11.2018 - 01.06.2021

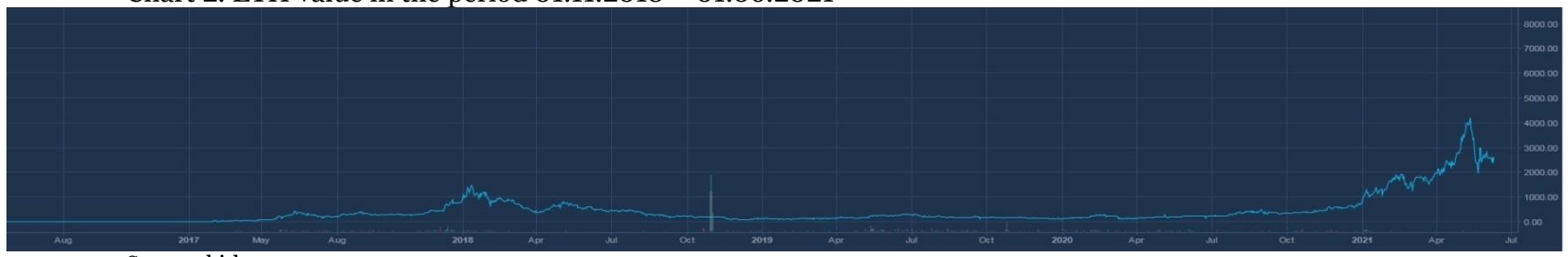

Source: bitbay.net.

Then, after analysing the cryptocurrency prices: ETH and BTC analysis of the tweet sentiment index regarding these cryptocurrencies. Sentiment analysis is a rapidly developing area of natural language processing and analysis. It is used in numerous business applications such as social media. This process enables the direct qualification of the emotional content from any set of text. There are two approaches to sentiment analysis. The first is the lexical approach. It is based on a predefined list of words that are closely related to emotions, which are referred to as lexicons. These, in turn, are classified into three categories: negative, neutral and positive. The second, more modern approach is based on Machine Learning (ML) techniques. ML is used to predict moods in a given set of texts. The ML technique in sentiment analysis allows exploring the weights to measure a given text fragment. The disadvantage of the ML technique in sentiment analysis is the need to have very large training data sets with meaning labels for individual phrases specific to a given sector. Building this type of database is extremely time-consuming and costly (Buckman et al. 2020 p. 2). The default positive and negative database was used in the sentiment analysis of this paper. This is confirmed by the study by A. Brochado (2020).

The aim of the study is to check whether messages in social media (Twitter) are relevant in the valuation of BTC and ETH cryptocurrencies. The second goal of the study is to check whether or not the value of the sentiment can show that the news in a given period of time may have an unpredictable impact on the prices of the above cryptocurrencies, and thus whether they are speculative.

\section{EMPIRICAL ANALYSIS - RESULTS AND DISCUSSION}

The following values were included in the analysis: price, number of Twitter users following the thread of individual cryptocurrencies, and positive and negative sentiment values. The study results are presented in Charts 3 and 4. 
The sentiment analysis clearly showed that the number and type of tweets for individual cryptocurrencies significantly affect their price. This means that one tweet can affect the price in an unpredictable way. With just one message, one tweet, an active, well-known celebrity (e.g. E. Musk, W. Buffet), or a fund with many followers may cause a change in the value of cryptocurrencies in a speculative way. Other users spreading information, re-sending or quoting affects the price of a given cryptocurrency to a significant extent. Moreover, the information shared by influential global politicians regarding the regulation of cryptocurrencies has a significant impact on the prices of BTC and ETH. Every piece of information and every rumour posted by users (whether true or false) has significant ramifications for the speculative price of these cryptocurrencies.

Chart 3. BTC sentiment analysis (price, number of BTC followers on Twitter, positive sentiment, negative sentiment)

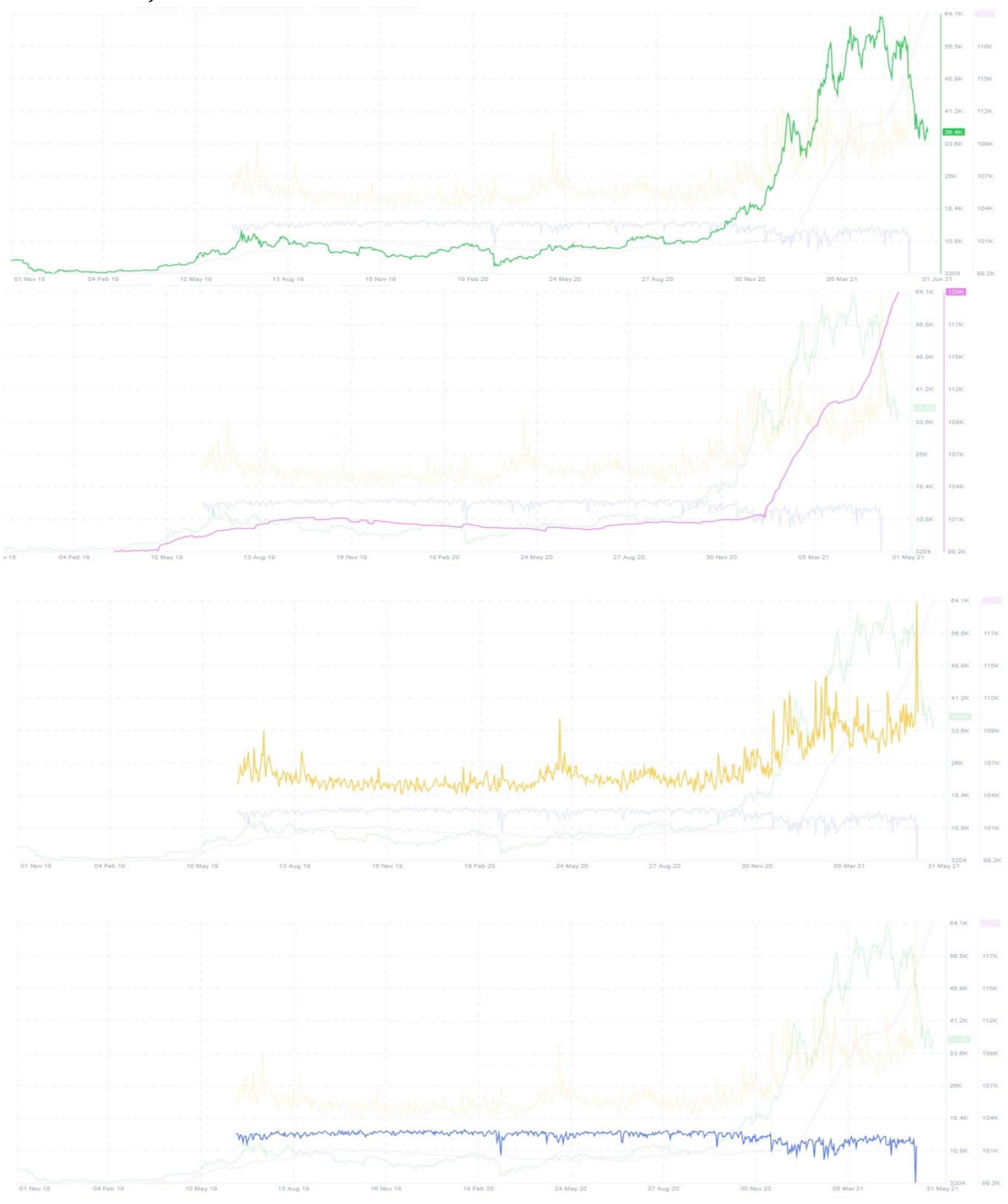


Chart 4. ETH sentiment analysis (price, number of ETH followers on Twitter, positive sentiment, negative sentiment)

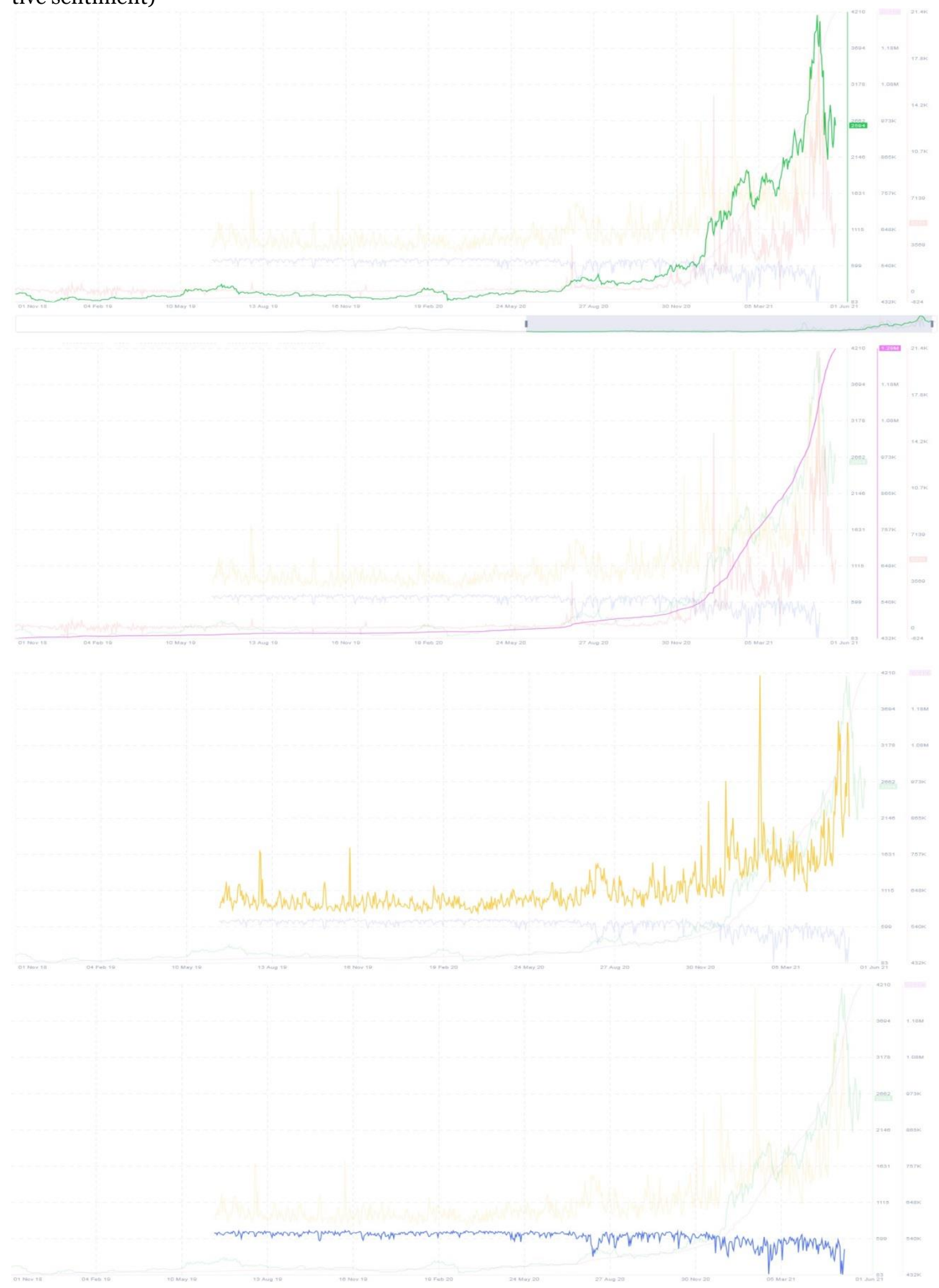

Source: Author's own work based on santiment.net. 


\section{CONCLUding Remarks}

The purpose of the paper was to answer two questions. The first was whether social media (Twitter) messages are important in the valuation of BTC and ETH. Having analysed the sentiment and breaking it down into positive and negative sentiment, it can be clearly stated that social media messages significantly affect the prices of digital currencies.

Raising the second question was closely related to the first one. Due to the fact that the first question has been validated, it is, therefore, legitimate to ask the second question and obtain an answer to it: Does the value of the sentiment indicate whether tweets may be speculative in nature or whether the person/fund sharing a tweet can expect an attempt to influence the valuation of BTC or ETH? The conducted analysis, which finds confirmation in the literature on the subject, confirms that messages in social media are speculative in nature. The spreading of negative or false information raises negative sentiments, which in turn causes a decrease in the value of the cryptocurrencies under analysis. The same is true for re-sending a positive sentiment message or trying to create a positive sentiment rumour. Such a tweet increases the value of cryptocurrencies.

It is recommended to conduct further research on the sentiment index not only on the cryptocurrency market but also on stock markets and stock exchange indices (including FOREX) because, as the analysed literature has shown, the concept of speculation is also present in these markets.

\section{REFERENCES}

Ahl, A., Yarime, M., Goto, M., Chopra, S. S., Kumar, N. M., Tanaka, K., \& Sagawa, D. (2020) Exploring blockchain for the energy transition: Opportunities and challenges based on a case study in Japan. Renewable and Sustainable Energy Reviews, 117, 109488.

Ahmed, Y. A., Ahmad, M. N., Ahmad, N., \& Zakaria, N. H. (2019) Social media for knowledge-sharing: A systematic literature review. Telematics and informatics, 37, 72-112.

Alammary, A., Alhazmi, S., Almasri, M., \& Gillani, S. (2019) Blockchain-based applications in education: A systematic review. Applied Sciences, 9(12), 2400.

Andoni, M., Robu, V., Flynn, D., Abram, S., Geach, D., Jenkins, D., McCallum P., Peacock, A. (2019) Blockchain technology in the energy sector: A systematic review of challenges and opportunities. Renewable and Sustainable Energy Reviews, 100, $143-174$.

Bermeo-Almeida, O., Cardenas-Rodriguez, M., Samaniego-Cobo, T., Ferruzola-Gómez, E., Cabezas-Cabezas, R., \& Bazán-Vera, W. (2018) Blockchain in agriculture: A systematic literature review. In International Conference on Technologies and Innovation (pp. 44-56). Springer, Cham.

Boniecki R., \& Rawłuszko J. (2017) Mozliwości wykorzystania technologii Blockchain w biznesie. Ekonomiczne Problemy Ustug.

Casey, M. J., \& Vigna, P. (2018) The truth machine: the blockchain and the future of everything. St. Martin's Press.

Grover, P., Kar, A. K., \& Janssen, M. (2019) Diffusion of blockchain technology. Journal of Enterprise Information Management.

Hart, C. (2018). Doing a literature review: Releasing the research imagination.

Kamble, S. S., Gunasekaran, A., \& Gawankar, S. A. (2020) Achieving sustainable performance in a data-driven agriculture supply chain: A review for research and applications. International Journal of Production Economics, 219, 179-194.

Kim, S. K., \& Huh, J. H. (2018) A study on the improvement of smart grid security performance and blockchain smart grid perspective. Energies, 11(8), 1973.

Kim, Y. M., Jung, D., Chang, Y., \& Choi, D. H. (2019) Intelligent micro energy grid in 5G era: Platforms, business cases, testbeds, and next generation applications. Electronics, 8(4), 468.

Kittipanya-Ngam, P., \& Tan, K. H. (2020) A framework for food supply chain digitalization: lessons from Thailand. Production Planning \& Control, 31(2-3), 158-172.

Li, J., Greenwood, D., \& Kassem, M. (2019) Blockchain in the built environment and construction industry: A systematic review, conceptual models and practical use cases. Automation in Construction, 102, 288-307.

Matusiak B.E. (2013) Modele biznesowe na nowym zintegrowanym rynku energii. Wydawnictwo Uniwersytetu Lódzkiego. Lódź.

McGhin, T., Choo, K. K. R., Liu, C. Z., \& He, D. (2019) Blockchain in healthcare applications: Research challenges and opportunities. Journal of Network and Computer Applications, 135, 62-75.

Mengelkamp, E., Gärttner, J., Rock, K., Kessler, S., Orsini, L., \& Weinhardt, C. (2018) Designing microgrid energy markets: A case study: The Brooklyn Microgrid. Applied Energy, 210, 870-880.

Nakamoto, S. (2019) Bitcoin: A peer-to-peer electronic cash system. Manubot.

Qian, J., Dai, B., Wang, B., Zha, Y., \& Song, Q. (2020) Traceability in food processing: problems, methods, and performance evaluations-a review. Critical Reviens in Food Science and Nutrition, 1-14.

Rejeb, A. (2018) Halal meat supply chain traceability based on HACCP, blockchain and internet of things. Acta Technica Jaurinensis, 11(1).

Rymarczyk, J. (2020) Technologies, Opportunities and Challenges of the Industrial Revolution 4.0: Theoretical Considerations, Entrepreneurial Business and Economics Review, 8(1), s.185-198.

Sawa, T. (2019) Blockchain technology outline and its application to field of power and energy system. Electrical Engineering in Japan, 206(2), 11-15.

Shankar, K. (2020) An optimal least square support vector machine based earnings prediction of blockchain financial products. IEEE Access, 8, 120321-120330. 
Talat, R., Muzammal, M., Qu, Q., Zhou, W., Najam-ul-Islam, M., Bamakan, S. H., \& Qiu, J. (2020) A decentralized system for green energy distribution in a smart grid. Journal of Energy Engineering, 146(1), 04019036.

Tan, A., \& Ngan, P. T. (2020) A proposed framework model for dairy supply chain traceability. Sustainable Futures, 2, 100034.

Teufel, B., Sentic, A., \& Barmet, M. (2019) Blockchain energy: Blockchain in future energy systems. Journal of Electronic Science and Technology, 17(4), 100011.

Tian, F. (2016) An agri-food supply chain traceability system for China based on RFID \& blockchain technology. In 2016 13th international conference on service systems and service management (ICSSSM) (pp. 1-6). IEEE.

Tijan, E., Aksentijević, S., Ivanić, K., \& Jardas, M. (2019) Blockchain technology implementation in logistics. Sustainability, 11(4), 1185.

Troncia, M., Galici, M., Mureddu, M., Ghiani, E., \& Pilo, F. (2019) Distributed ledger technologies for peer-to-peer local markets in distribution networks. Energies, 12(17), 3249.

Wang, Q., \& Su, M. (2020) Integrating blockchain technology into the energy sector-from theory of blockchain to research and application of energy blockchain. Computer Science Review, 37, 100275.

Wang, Q., Li, R., \& Zhan, L. (2021) Blockchain technology in the energy sector: From basic research to real world applications. Computer Science Review, 39, 100362.

Wang, S., Taha, A. F., Wang, J., Kvaternik, K., \& Hahn, A. (2019) Energy crowdsourcing and peer-to-peer energy trading in blockchain-enabled smart grids. IEEE Transactions on Systems, Man, and Cybernetics: Systems, 49(8), 1612-1623.

Weking, J., Mandalenakis, M., Hein, A., Hermes, S., Böhm, M., \& Krcmar, H. (2019) The impact of blockchain technology on business models-a taxonomy and archetypal patterns. Electronic Markets, 1-21.

Zhu, S., Song, M., Lim, M. K., Wang, J., \& Zhao, J. (2020) The development of energy blockchain and its implications for China's energy sector. Resources Policy, 66, 101595. 
CONFLICT OF INTEREST:

The authors declare that they have no material or financial interests associated with the research presented in this article. The authors declare that the study was conducted in the absence of any commercial or financial relationship giving rise to a conflict of interest.

\section{COPYRIGHT AND LICENSE:}

\section{(c) (1) $\Theta$}

This article is published under the terms of the Creative Commons

Attribution - NoDerivs (CC BY-ND 4.0) License

http://creativecommons.org/licenses/by-nd/4.o/

Published by Podhale State College of Applied Sciences - Nowy Targ, Poland 